\title{
Hypoxia-Inducible Transcription Factor $2 \alpha$ Promotes Steatohepatitis Through Augmenting Lipid Accumulation, Inflammation, and Fibrosis
}

\author{
Aijuan $Q u,{ }^{1}$ Matthew Taylor, ${ }^{2}$ Xiang Xue, ${ }^{2}$ Tsutomu Matsubara, ${ }^{1}$ Daniel Metzger, ${ }^{4}$ Pierre Chambon, ${ }^{4}$ \\ Frank J. Gonzalez, ${ }^{1}$ and Yatrik M. Shah ${ }^{2,3}$
}

\begin{abstract}
Oxygen dynamics in the liver is a central signaling mediator controlling hepatic homeostasis, and dysregulation of cellular oxygen is associated with liver injury. Moreover, the transcription factor relaying changes in cellular oxygen levels, hypoxia-inducible factor (HIF), is critical in liver metabolism, and sustained increase in HIF signaling can lead to spontaneous steatosis, inflammation, and liver tumorigenesis. However, the direct responses and genetic networks regulated by HIFs in the liver are unclear. To help define the HIF signal-transduction pathway, an animal model of HIF overexpression was generated and characterized. In this model, overexpression was achieved by Von Hippel-Lindau ( $V h l)$ disruption in a liverspecific temporal fashion. Acute disruption of $V h l$ induced hepatic lipid accumulation in an HIF- $2 \alpha$-dependent manner. In addition, HIF- $2 \alpha$ activation rapidly increased liver inflammation and fibrosis, demonstrating that steatosis and inflammation are primary responses of the liver to hypoxia. To identify downstream effectors, a global microarray expression analysis was performed using livers lacking $V b l$ for 24 hours and 2 weeks, revealing a timedependent effect of HIF on gene expression. Increase in genes involved in fatty acid synthesis were followed by an increase in fatty acid uptake-associated genes, and an inhibition of fatty acid $\beta$-oxidation. A rapid increase in proinflammatory cytokines and fibrogenic gene expression was also observed. In vivo chromatin immunoprecipitation assays revealed novel direct targets of HIF signaling that may contribute to hypoxia-mediated steatosis and inflammation. Conclusion: These data suggest that HIF- $2 \alpha$ is a critical mediator in the progression from clinically manageable steatosis to more severe steatohepatitis and liver cancer, and may be a potential therapeutic target. (НЕРATOLOGY 2011;54:472-483)
\end{abstract}

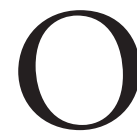
xygen is a critical signaling molecule that regulates the metabolic activities of the liver. ${ }^{1,2}$ Dysregulation of the normal oxygen gradient in the liver can induce liver steatosis and inflammation. ${ }^{2}$ Decreased cellular oxygen affects gene expression through the transcription factor, hypoxia-inducible factor (HIF). During normal cellular oxygen levels, HIF $\alpha$ subunits are rapidly degraded by the ubiquitin proteasome system in which Von Hippel-Lindau (VHL) tumor suppressor protein is the critical E3 ubiquitin

Abbreviations: A2M, $\alpha$-2-macroglobulin; ACOX, acyl-CoA oxidase 1; ADFP, adipose differentiation-related protein; ANGPTL3, angiopoietin-like 3; ARNT, aryl hydrocarbon nuclear translocator; CPT1A, carnitine palmitoyltransferase 1A; CPT2, carnitine palmitoyltransferase 2; ChIP, chromatin immunoprecipitation; COL1A1, collagen 1a1; COL3A1, collagen 3a1; COL4A1, collagen 4a1; COL4A2, collagen 4a2; COL5A2, collagen 5a2; COL12A1, collagen 12a1; CTGF, connective tissue growth factor; FASN, fatty acid synthase; EPO, erythropoietin; H\&E, hematoxylin and eosin; HIF, hypoxia-inducible factor; IgG, immunoglobulin G; IL-1 $\beta$, interleukin-1 $\beta$; IL-6, interleukin-6; IGFBP1, insulin-like growth factor binding protein-1; LOXL1, lysyl oxidase-like 1; LOXL2, lysyl oxidase-like 2; PPAR $\alpha$, peroxisome proliferator-activated receptor alpha; P4HA1, prolyl 4-hydroxylase alpha 1; P4HA2, prolyl 4-hydroxylase alpha 2; PLOD2, procollagen-lysine, 2-oxoglutarate 5-dioxygenase 2; PDK1, pyruvate dehydrogenase kinase 1; qRT-PCR, quantitative real-time reverse-transcriptase polymerase chain reaction; SMA, smooth muscle actin; SREBP-1C, sterol regulatory element binding factor-1C; SD, standard deviation; TIMP1, tissue inhibitor of metallopeptidase 1; TGFB1, transforming growth factor b1; TGM2, transglutaminase 2; VHL, Von Hippel-Lindau tumor suppressor protein.

From the ${ }^{1}$ Laboratory of Metabolism, Center for Cancer Research, National Cancer Institute, National Institutes of Health, Bethesda, MD; ${ }^{2}$ Department of Molecular and Integrative Physiology, ${ }^{3}$ Department of Internal Medicine, Division of Gastroenterology, University of Michigan, Ann Arbor, MI; and ${ }^{4}$ Department of Physiological Genetics, Institut de Génétique et de Biologie Moléculaire et Cellulaire, Illkirch, France.

Received February 28, 2011; accepted April 17, 2011.

This study was supported by grants from the National Institutes of Health (CA148828), The University of Michigan Gastrointestinal Peptide Center (to Y.M.S.), and the National Cancer Institute Intramural Research Program.

Address reprint requests to: Yatrik M. Shah, Ph.D., Department of Molecular and Integrative Physiology, Department of Internal Medicine, Division of Gastroenterology, University of Michigan, 1301 East Catherine Street, Ann Arbor, MI 48109. E-mail: shahy@umich.edu; fax: 734-936-8813. 
ligase required for HIF degradation. ${ }^{3-8}$ HIF- $1 \alpha$ and HIF- $2 \alpha$ regulate the expression of genes critical for adaptation to low oxygen levels. Targeted disruption of $V h l$ in the liver increased HIF- $1 \alpha$ and HIF- $2 \alpha$ expression, and this mouse model has demonstrated that HIFs are critical in erythropoiesis, iron metabolism, hepatic lipid homeostasis, glucose metabolism, and tumor formation in the liver. ${ }^{9-14}$ Because overexpression of HIF through disruption of $V h l$ has many robust pleiotropic effects, it is difficult to assess which are the direct responses of the liver after hypoxia. Furthermore, finding direct mediators of HIF signaling in the liver, which contribute to the phenotype, has been difficult. To overcome this problem, we describe a liver-specific temporal disruption of $V h l$ using a cre$\mathrm{ER}^{\mathrm{T} 2}$ system, which activates a liver-specific cre recombinase expression in the presence of the estrogen ana$\log$, tamoxifen. Acute disruption of $V h l$ resulted in a robust accumulation of lipids in the liver and an increase in liver inflammation and fibrosis. Using a compound double deletion of $\mathrm{Vhl}$ and $\mathrm{Hif}-1 \alpha$ or Hif$2 \alpha$, liver steatosis, inflammation, and fibrosis were mediated in a HIF- $2 \alpha$-dependent manner. To assess direct signaling pathways activated by HIF, global gene expression analysis was performed in the livers of mice with a temporal disruption of $\mathrm{Vhl}$ for 24 hours or 2 weeks. Gene expression profiles demonstrated that HIF rapidly regulates a large battery of genes important for fatty acid synthesis, uptake, and $\beta$-oxidation. Moreover, several proinflammatory mediators and profibrogenic genes were rapidly activated after $V h l$ deletion. These data demonstrate that liver injury resulting from hypoxia is a primary response mediated by HIF- $2 \alpha$.

\section{Materials and Methods}

Luciferase Assay. The mouse angiopoietin-like 3 (Angptl3)-promoter luciferase was previously described. ${ }^{15}$ Mouse transglutaminase 2 ( $\operatorname{Tgm} 2$ )-reporter plasmid was constructed by cloning the upstream regions into pGL3basic vector (Promega, Madison, WI), using primers listed in Supporting Table 1. These luciferase reporters were transfected into Hepa-1 cells, and luciferase assays were performed as previously described. ${ }^{16}$

Animals and Diets. $V h l^{\mathrm{F} / \mathrm{F}}, V h l^{\mathrm{F} / \mathrm{F}} H i f-1 \alpha^{\mathrm{F} / \mathrm{F}}$, and $V h l^{\mathrm{F} / \mathrm{F}}$ Hif- $2 \alpha^{\mathrm{F} / \mathrm{F}}$ were previously described. ${ }^{16}$ For temporal hepatocyte-specific disruption, $V h t^{\mathrm{F} / \mathrm{F}}, V h t^{\mathrm{F} / \mathrm{F}} H$ if-
$1 \alpha^{\mathrm{F} / \mathrm{F}}$, and $V h l^{\mathrm{F} / \mathrm{F}} H i f-2 \alpha^{\mathrm{F} / \mathrm{F}}$ mice were crossed with mice harboring the Cre-ER ${ }^{\mathrm{T} 2}$ recombinase under control of the albumin promoter, SA-Cre-ER ${ }^{\mathrm{T} 2} .{ }^{17}$ The mice are a mixed Sv129 and C57BL/6 background, and wild-type littermate control mice were used as a comparison for each experiment. Mice were used between the ages of 6 and 8 weeks for all experiments. For activation of the SA-Cre-ER ${ }^{\mathrm{T} 2}$ recombinase for shortterm experiments (i.e., 1 and 3 days), mice were treated with 1 dose of tamoxifen ( $2 \mathrm{mg} / \mathrm{mouse}$ in corn oil) by intraperitoneal (IP) injection and killed 24 hours or 3 days after tamoxifen treatment. For the 7-day and 2-week experiments, mice were fed tamoxifen in the diet for 2 days, then replaced with regular chow and killed at 7 days or 2 weeks after initial tamoxifen administration. For the alcohol treatment, mice were treated with tamoxifen by IP injection on 2 consecutive days, then were fed, ad libitum, a 4\% alcohol-containing liquid diet (LieberDeCarli Diet; Dyets, Inc., Bethlehem, PA) and killed 2 weeks after alcohol administration. Mice were housed in temperature- and light-controlled rooms and were given water and pelleted chow ad libitum. All animal studies were carried out in accordance with guidelines and approved by the National Cancer Institute and University of Michigan Animal Care and Use Committee.

RNA Analysis. RNA was extracted from tissues, reverse transcribed, and quantitative real-time reversetranscriptase polymerase chain reaction (qRT-PCR) was performed using primer sequences listed in Supporting Table 1.

Western Blot Analysis. Liver whole-cell or nuclear extracts were prepared. Membranes were incubated with antibodies against HIF- $1 \alpha$, HIF- $2 \alpha$ (Novus Biologicals, Littleton, CO), ANGPTL3 (Santa Cruz Biotechnology, Inc., Santa Cruz, CA), and smooth muscle actin (SMA) (Sigma, St. Louis, MO), phophorylated, and total acetyl-CoA carboxylase (ACC) (Cell Signaling Technology, Beverly, MA) signals obtained were normalized to GAPDH (Santa Cruz) for whole cell extract and histone H1 (Santa Cruz), pregnane $\mathrm{X}$ receptor (PXR), and hepatic nuclear factor 4 (HNF- $4 \alpha$ ) (Abcam, Cambridge, MA) for nuclear extracts.

cDNA Microarray Analysis. Liver cDNAs were hybridized to an Agilent $44 \mathrm{~K}$ mouse 60-peptide oligomer microarray (Agilent Technologies, Santa Clara, CA). Data were processed and analyzed by a Genespring GX software package (Agilent Technologies). 
Immunohistochemistry. Hematoxylin and eosin $(\mathrm{H} \& \mathrm{E})$ and Masson's trichrome staining were performed on formalin fixed paraffin embedded sections. Oil red $\mathrm{O}$ staining was performed on frozen liver sections or adherent hepatoma-derived Hepa-1 cells. For quantification of oil red $\mathrm{O}$ in Hepa-1 cells, isopropanol was added to the cells after staining. Absorbance was measured at $510 \mathrm{~nm}$ in the isopropanol extracts, and values were normalized to protein content.

Triglyceride and Cholesterol Analysis. Hepatic lipids were extracted using a 2:1 chloroform-methanol solution. Liver and serum triglycerides were measured using the Serum Triglyceride and Cholesterol Determination Kit, according to the manufacturer's recommendation (Wako, Richmond, VA).

ChIP Assays. Livers were cross-linked in 1\% formaldehyde in $1 \times$ phosphate-buffered saline at $37^{\circ} \mathrm{C}$ for 20 minutes. ChIP assays were performed for HIF- $2 \alpha$ as previously described. ${ }^{16}$ Primers for qRT-PCR ChIP are available upon request. The primers for Tgm2 ChIP are listed in Supporting Table 1.

Data Analysis. Results are expressed as mean \pm standard deviation (SD). $P$ values were calculated by independent $t$ test. $P<0.05$ was considered significant.

\section{Results}

Generation of a Mouse Model Containing a Temporal Hepatocyte-specific Disruption of Vhl. $V h \mathrm{~F}^{\mathrm{F} / \mathrm{F}}$ mice were crossed with SA-Cre-ER ${ }^{\mathrm{T} 2}$ transgenic mice to generate a temporal and conditional disruption of $V h l\left(V h t^{\mathrm{F} / \mathrm{F} ; \mathrm{AlbER} c r e}\right)$. The tamoxifen-inducible Cre provides an advantage of assessing immediate downstream pathways controlled by VHL and eliminates the confounding developmental effects of $V h l$ deletion. To confirm the inducibility and hepatocyte-specific disruption, $V h l^{\mathrm{F} / \mathrm{F}}$ and $V h l^{\mathrm{F} / \mathrm{F} ; \text { AlbERcre }}$ mice were treated with one dose of vehicle or tamoxifen, and livers and extrahepatic tissues were isolated 24 hours post-treatment. $V h l^{F / F}$ and $V h l^{F / F ; A l b E R c r e}$ mice treated with vehicle did not demonstrate a decrease in $V h l$ gene expression, whereas tamoxifen treatment dramatically decreased $V h l$ gene expression in the $V h l^{\mathrm{F} / \mathrm{F} \text {;AlbERcre }}$ but not the $V h t^{\mathrm{F} / \mathrm{F}}$ mice (Fig. 1A). Moreover, the decrease was specific for the liver; no other tissues assessed demonstrated a tamoxifen-dependent decrease in $V h l$ expression (Supporting Fig. 1). Western blot analysis of nuclear extracts demonstrated an increase in HIF- $1 \alpha$ and HIF-2 $\alpha$ expression (Fig. 1B). Consistent with $\mathrm{HIF} \alpha$ subunit expression, an increase in pyruvate dehydrogenase kinase 1 (Pdk1) and erythropoietin (Epo), two well-characterized HIF- $1 \alpha$ and HIF- $2 \alpha$ target genes, were observed (Fig. 1C). In mice that contained a conditional disruption of $\mathrm{Vhl}$, increased liver and spleen weights were noted at 6-8 weeks of age. ${ }^{9,11}$ Therefore, to assess whether these were early events after loss of VHL, liver and spleen weights were measured in mice in which $V h l$ was disrupted for 14 days. A significant increase in liver and spleen weights was observed (Fig. 1D-F). Together, these data demonstrate that tamoxifen-inducible $V h l$ disruption is an optimal system to assess primary responses, which are critical in hypoxia-induced liver injury.

HIF-2 $\alpha$ Increases Inflammation and Lipid Accumulation in the Liver. Conditional inactivation of $V h l$ in hepatocytes results in liver inflammation and hepatic steatosis. ${ }^{9,11,14}$ However, it is not clear whether inflammation and lipid accumulation are early events after disruption of $\mathrm{Vhl}$ or are results of the developmental or chronic effects from loss of $V h l$. To address these questions, livers were analyzed after disruption of $\mathrm{Vhl}$ for 2 weeks; a robust increase in liver inflammation was observed by H\&E staining and qRT-PCR analysis of two proinflammatory mediators: interleukin- $1 \beta(I l-1 \beta)$ and $\mathrm{Il}-6$ (Fig. 2A-C). The increase in Il-6 and $\mathrm{Il}-1 \beta$ gene expression was evident as early as 3 days after tamoxifen treatment (Fig. 2D). Overt inflammation, as observed by H\&E staining, was evident at 7 days after tamoxifen treatment (Supporting Fig. 2A). To assess the influence of HIF-dependent pathways on inflammatory gene expression in the liver, mice with a double disruption of $V h l$ and Hif- $1 \alpha$ or $H$ if- $2 \alpha$ were generated. The double disruption of $V h l$ and Hif- $2 \alpha\left(\right.$ Vht $^{\mathrm{F} / \mathrm{F}} H$ if $2 a^{\mathrm{F} / \mathrm{F} ; \mathrm{AlbER} c r e}+$ tamoxifen $)$ ameliorated the increase in $\mathrm{Il}-6$ and $\mathrm{Il}-1 \beta$, compared to littermate controls (Vht ${ }^{\mathrm{F} / \mathrm{F}}$ Hif $2 a^{\mathrm{F} / \mathrm{F}}+$ tamoxifen) (Fig. 2E). In contrast, a significant increase in $\mathrm{Il}-6$ and $\mathrm{Il}-1 \beta$ gene expression was observed in mice with a double disruption of $V h l$ and Hif-1 $\alpha$, compared to littermate controls (Supporting Fig. 2B). Furthermore, 2 weeks after the loss of $V h l$, a dramatic increase in liver lipid accumulation was observed by oil red $\mathrm{O}$ staining (Fig. 3A,B). The increase in lipid accumulation could be observed as early as 24 hours after $V h l$ disruption (Fig. 3C,D). The compound disruption of $V h l$ and Hif- $1 \alpha$ or Hif- $2 \alpha$ demonstrated that the increase in lipid accumulation was caused by HIF- $2 \alpha$, but not HIF-1 $\alpha$ (Fig. 3E,F). Consistent with oil red O staining, hepatic triglycerides and cholesterol increased after disruption of $\mathrm{Vhl}$ for 2 weeks (Fig. 3G). Together, these data demonstrate that HIF- $2 \alpha$ is a direct regulator of liver inflammation and lipid accumulation in the liver. 

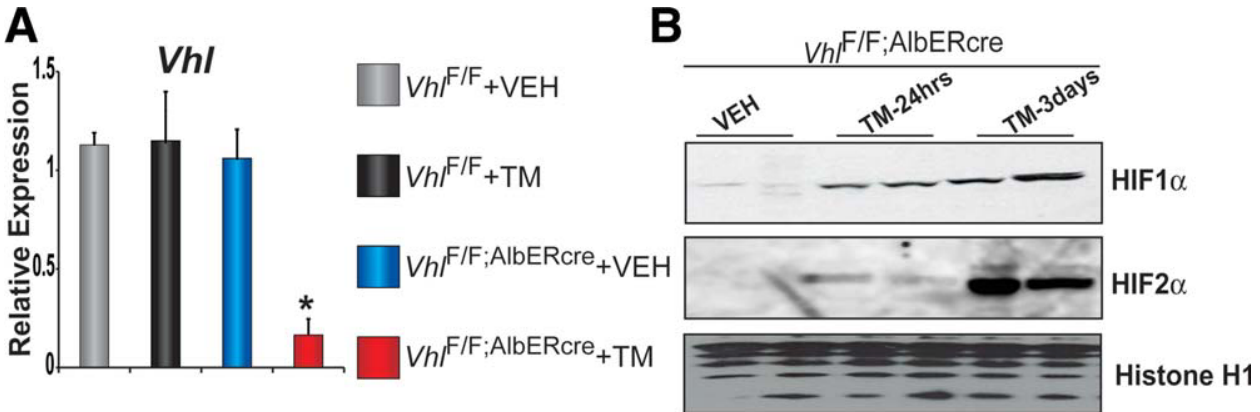

D

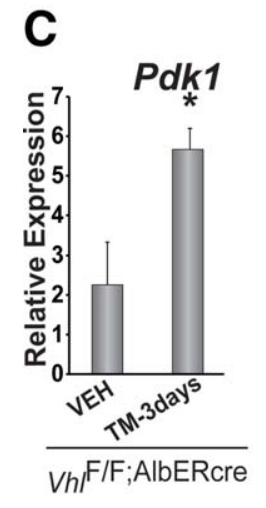

\section{E}

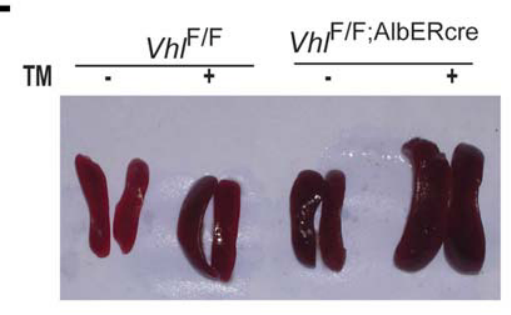

Epo
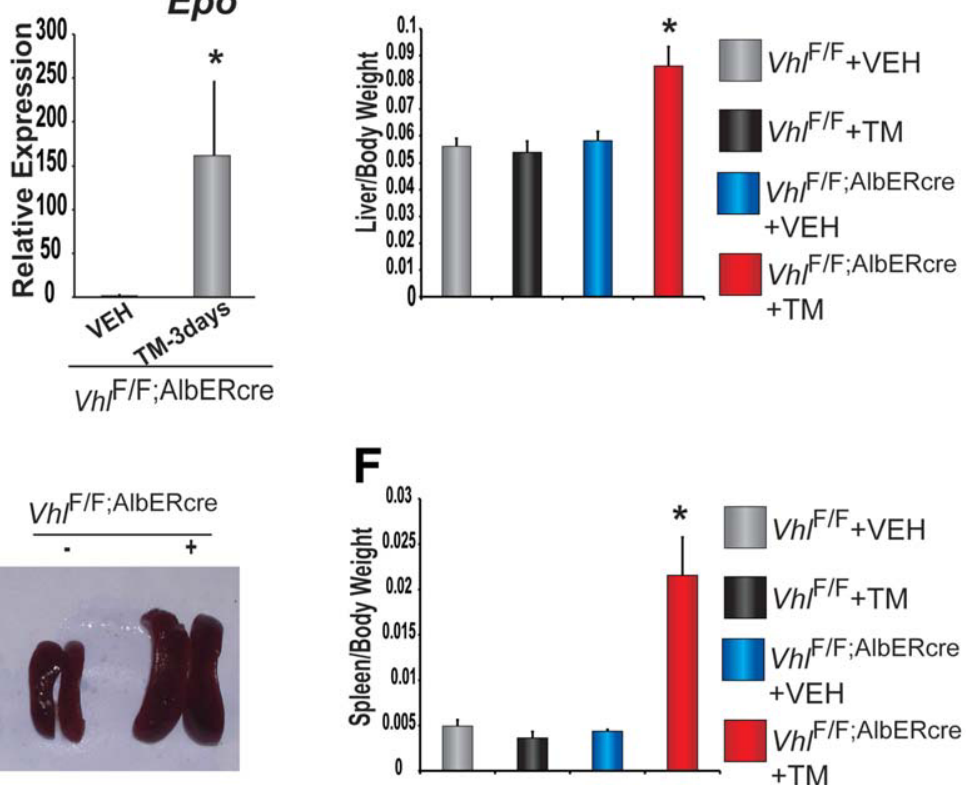

Fig. 1. Conditional and temporal disruption of $\mathrm{Vhl}$ in hepatocytes leads to HIF- $1 \alpha$ and HIF-2 $\alpha$ activation. (A) qRT-PCR analysis measuring liver

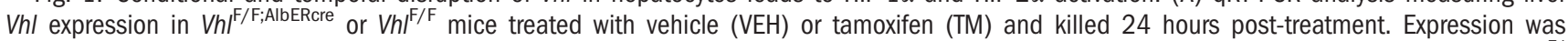
normalized to $\beta$-actin. Seven to nine mice were assessed per each treatment group. (B) Western blot analysis in liver nuclear extracts in $\mathrm{Vh}^{\mathrm{F} /}$ F;AlbERcre mice treated with VEH and TM and killed 24 hours and 3 days post-treatment. Expression was normalized to Histone H1 protein expression. (C) qRT-PCR analysis measuring liver pyruvate dehydrogenase kinase 1 (Pdk1) and erythropoietin (Epo) expression in Vhl ${ }^{\mathrm{F} / \mathrm{F} ; \mathrm{AlbER} c \mathrm{re}}$ mice treated with VEH or TM at 3 days post-treatment. Expression was normalized to $\beta$-actin. Seven to nine mice were assessed per each treatment group. (D) Liver weight analysis in $V h l^{\mathrm{F} / F ; A l b E R c r e}$ or $\mathrm{Vh} \mathrm{F}^{\mathrm{F} / \mathrm{F}}$ mice treated with $\mathrm{VEH}$ or TM and killed 14 days post-treatment. Liver weights were normalized to body weights. Seven to nine mice were assessed per each treatment group. (E,F) Spleen weight analysis in $V h l^{\mathrm{F} / F ; A l b E R c r e}$ or $V h l^{\mathrm{F} / \mathrm{F}}$ mice treated with VEH or TM and killed 14 days post-treatment. (F) Spleen weights were normalized to body weights. Seven to nine mice were assessed per each treatment group. Each bar graph represents the mean value \pm SD. ${ }^{*} P<0.05$.

HIF-Regulated Genetic Program in the Liver. To understand the critical genes regulated after $V h l$ disruption, gene expression profiles of $V h t^{F / F}$ and $V h t^{F / F ; A l b E R c r e ~}$ were assessed in livers isolated 24 hours or 2 weeks after Vhl disruption. In total, 3597 significantly regulated changes were identified after 2 weeks of $V h l$ deletion, whereas 470 genes were identified 24 hours after $V h l$ disruption (Fig. 4A; the full gene list with an average change of 1.5-fold is in Supporting Tables 2 and 3). The data suggested that a rapid increase in genes critical for lipid synthesis was followed by an increase in genes important for fatty acid uptake. Consistent with the microarray data, an increase was observed in the expression of fatty acid synthase (Fasn) and sterol regulatory element binding factor-1C (Srebp-1c) at 3 days after Vhl disruption. Interestingly, at 14 days after $V h l$ disruption, a significant repression of Fasn and Srebp-1c was observed (Fig. 4B), whereas a rapid repression of Cd36 gene expression was observed after 3 days of $V h l$ disruption, followed by a dramatic increase in gene expression 14 days after the loss of $V h l$ (Fig. 4B). In addition, a significant decrease was observed in genes critical in fatty acid $\beta$-oxidation, and a decrease in carnitine palmitoyltransferase 1A (Cpt1a), carnitine palmitoyltransferase 2 (Cpt2), acyl-CoA oxidase 1 (Acox), and peroxisome proliferatoractivated receptor alpha (Ppar $\alpha)$ were observed after 2 

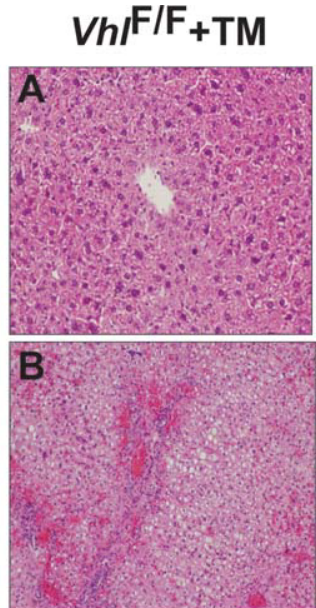

Vh/F/F;AlbERcre+TM

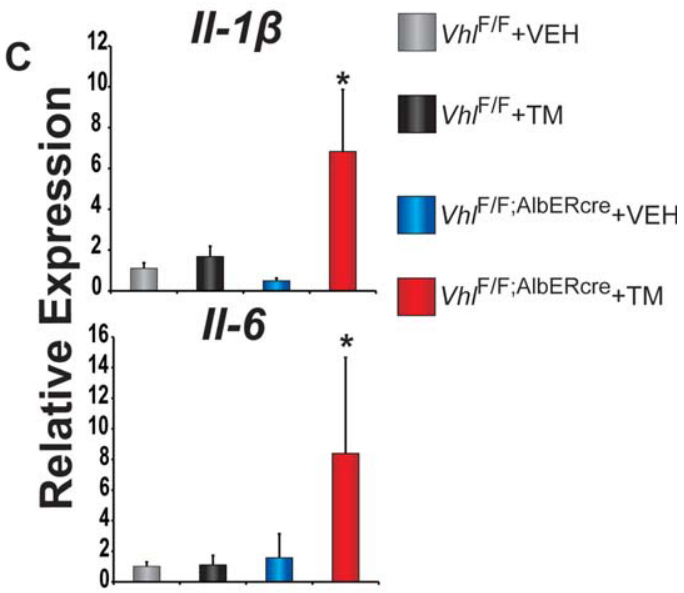

D
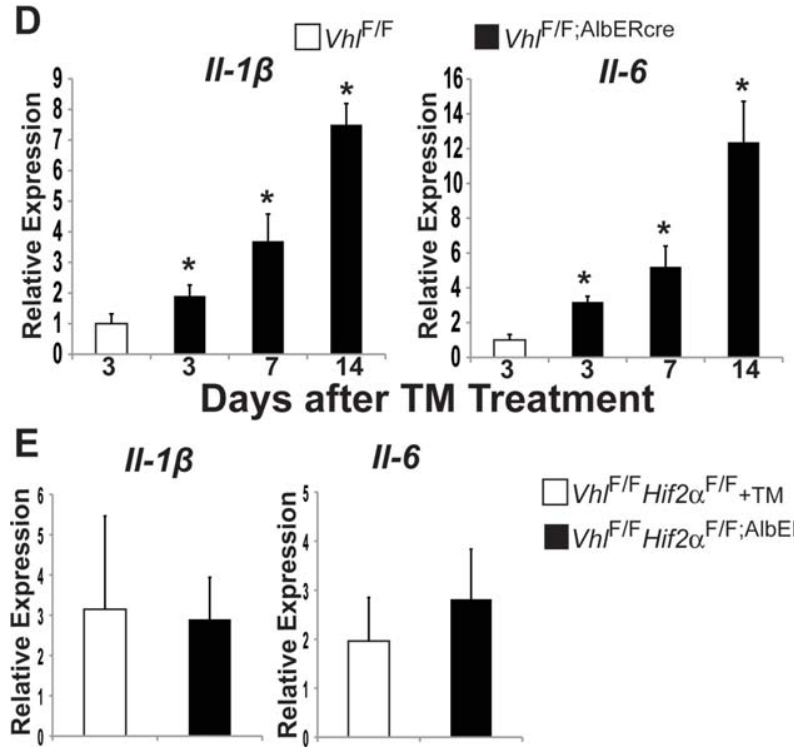

II-6

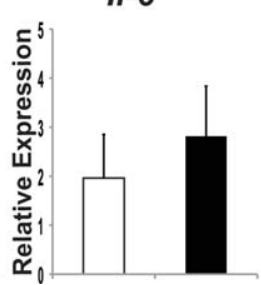

$$
\begin{aligned}
& \square v h h^{\mathrm{F} / F} H_{i f 2} \alpha^{\mathrm{F} / \mathrm{F}}+\mathrm{TM} \\
& \square V h f^{\mathrm{F} / \mathrm{F}} H_{i f 2} \alpha^{\mathrm{F} F ; \text { AlbERcre }_{+} \mathrm{TM}}
\end{aligned}
$$

Fig. 2. HIF- $2 \alpha$ induces liver inflammation. $\mathrm{H} \& \mathrm{E}$-stained liver sections from $(\mathrm{A}) \mathrm{Vh} \mathrm{F}^{\mathrm{F} / \mathrm{F}}$ and (B) $V h l^{F / F ; A l b E R c r e ~ m i c e ~ t r e a t e d ~ w i t h ~ t a m o x i f e n ~}$ (TM) and killed 14 days post-treatment. Seven to nine mice were assessed per each treatment group. (C) qRT-PCR analysis measuring liver $\| I-6$ and $I-1 \beta$ expression in $V h I^{F / F}$ and $V h l^{\mathrm{F} / F \text {; AlbERcre }}$ mice treated with vehicle (VEH) or TM and killed 14 days post-treatment. Expression was normalized to $\beta$-actin. Seven to nine mice were assessed per each treatment group. (D) qRT-PCR analysis measuring liver $\| 1-6$ and $I I-1 \beta$ expression in $V h l^{F / F}$ and $\mathrm{Vhl} \mathrm{F}^{\mathrm{F} F \text {;AlbERcre }}$ mice treated with TM and killed 3,7 , and 14 days post-treatment. Expression was normalized to $\beta$-actin. Seven to nine mice were assessed per each treatment group. (E) qRT-PCR analysis measuring liver II6 and $I-1 \beta$ expression in $V h F^{\mathrm{F} / \mathrm{F}} H i f 2 \alpha^{\mathrm{F} / \mathrm{F}}$ and $\mathrm{Vhl}^{\mathrm{F} / \mathrm{F}}$ Hif2 $\alpha^{\mathrm{F} / \mathrm{F} ; \mathrm{AlbER} \text { cre }}$ mice treated with TM and killed 14 days post-treatment. Expression was normalized to $\beta$-actin. Seven to nine mice were assessed per each treatment group. Each bar graph represents the mean value $\pm \mathrm{SD} .{ }^{*} P<0.05$. weeks of $V h l$ disruption; Ppar $\alpha$ expression did not reach statistical significance (Fig. 4C). Interestingly, the expression of PPAR $\alpha$ protein was significantly decreased 2 weeks after $V h l$ disruption, suggesting enhanced degradation (Fig. 4D). Expression of two other important nuclear receptors, PXR and HNF- $4 \alpha$, was unchanged. The decrease in $\beta$-oxidation genes was not observed at 3 days after $V h l$ disruption, but was dependent on HIF-2 $\alpha$ expression (Supporting Fig. 3). These data suggest that HIF- $2 \alpha$ regulates fatty acid synthesis, uptake, and $\beta$-oxidation in a time-dependent manner.

HIF-2 $\alpha$ Is a Novel Regulator of Angptl3. SREBP1c, FASN, CD36, and PPAR $\alpha$ have critical roles of in fatty acid homeostasis in the liver; however, their geneexpression patterns suggest that these genes may not be direct targets for HIF- $2 \alpha$ in the liver. Interestingly, angiopoietin-like 3 (Angptl3) demonstrated rapid, sus- tained increase after $\mathrm{Vhl}$ disruption (Fig. 5A). ANGPTL3 is specifically expressed in the liver and is a direct regulator of lipid homeostasis. ${ }^{18-20}$ Mutations in Angptl3 in mice or humans are associated with low serum lipid levels, whereas overexpression of ANGPTL3 increases circulating lipid levels. ${ }^{18,20}$ In mice with a double disruption of $V h l$ and Hif- $2 \alpha$, it was demonstrated that the induction of Angptl3 was the result of HIF- $2 \alpha$ increase (Supporting Fig. 4). Gene-expression data correlated to an increase in protein expression, as tamoxifen-treated $V h l^{\mathrm{F} / \mathrm{F} ; \mathrm{AlbER} \text { cre }}$ mice demonstrated an increase in liver ANGPTL3 protein expression, compared to tamoxifen-treated $V h l^{\mathrm{F} / \mathrm{F}}$ mice (Fig. 5B). Because mouse models that overexpress ANGPTL3 demonstrated an increase in serum lipid levels, ${ }^{20}$ serum triglycerides were assessed in mice 2 weeks after the loss of $V h l$. $V h l^{\mathrm{F} / F}$;AlbERcre mice treated with tamoxifen had elevated serum triglycerides, compared to similarly 


\section{$V h / F / F+T M$}

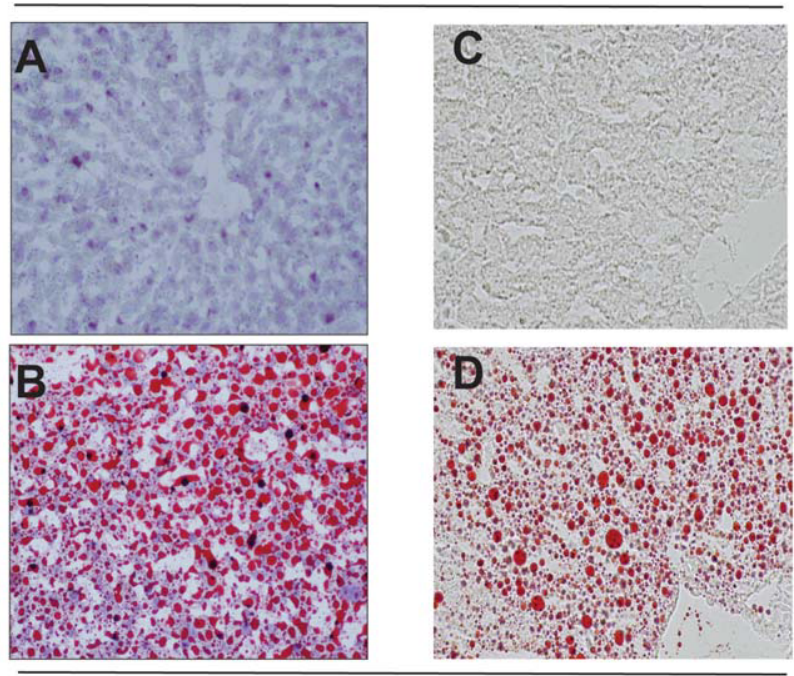

$V h{ }^{F / F ; A l b E R c r e}+$ TM
$V h / F / F_{H i f 1 \alpha} F / F$; AlbERcre+TM
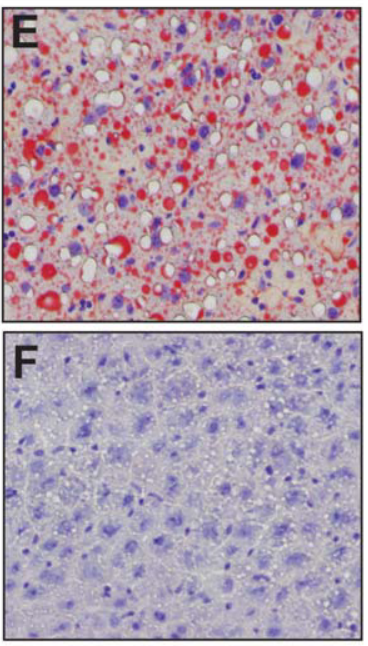

$V h / F / F_{H i f 2 \alpha} F / F$ AlbERcre+TM
Fig. 3. HIF- $2 \alpha$ increases lipid accumulation in the liver. Oil red 0 staining of livers isolated from $\mathrm{Vh} \mathrm{l}^{\mathrm{F} / \mathrm{F}}$ and $V h F^{F / F ; A l b E R c r e ~ m i c e ~ t r e a t e d ~ w i t h ~}$ tamoxifen (TM) and killed (A,B) 14 days or $(C, D) 24$ hours post-treatment. (E,F) Oil red 0 staining of livers isolated from (E) $V h l^{\mathrm{F} / \mathrm{F}}$ Hif1 $\alpha^{\mathrm{F} / \mathrm{F} \text {; AlbERcre }}$ and (F) $\quad \mathrm{Vhl}^{\mathrm{F} / \mathrm{F}} H \mathrm{Hif2} \alpha^{\mathrm{F} / \mathrm{F} ; \mathrm{AlbER} \text { cre }}$ mice treated with TM and killed 14 days post-treatment. (G) Hepatic lipid analysis was performed in livers isolated from $V h l^{\mathrm{F} / \mathrm{F}}$ and $V h F^{\mathrm{F} / \mathrm{F} \text { AlbERcre mice }}$ treated with TM and killed 14 days post-treatment. Each bar graph represents the mean value $\pm \mathrm{SD}$. ${ }^{*} P<$ 0.05 . Five to seven mice were assessed per each treatment group.

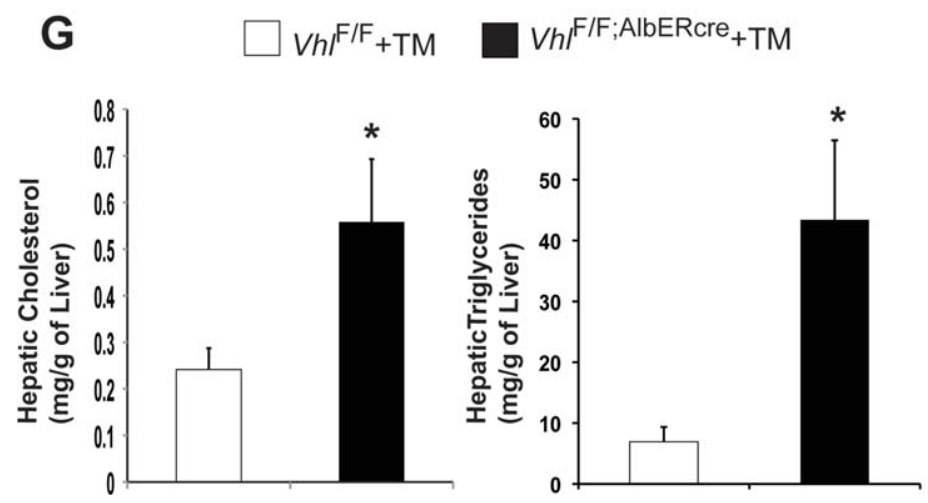

treated $V h t^{\mathrm{F} / \mathrm{F}}$ mice (Fig. 5C). In addition, liverderived Hepa-1 cells, which overexpress ANGPTL3, demonstrated a dose-dependent increase in oil red $\mathrm{O}$ accumulation, suggesting that ANGPTL3 may play a critical role in HIF-mediated lipid accumulation (Fig. 5D). To assess whether ANGPTL3 could be a novel direct target of HIF-2 $\alpha$, Angptl3-promoter luciferase assays were performed. A 1.7-kilobase (kb) Angptl3 proximal promoter luciferase construct was transfected into Hepa-1 cells. Hypoxia $\left(1 \% \mathrm{O}_{2}\right)$ induced luciferase expression (Fig. 5E), and cotransfection with a mammalian expression plasmid for HIF- $1 \alpha$ moderately increased luciferase expression, whereas cotransfection with HIF- $2 \alpha$ expression plasmid strongly increased luciferase expression. The HIF- $1 \alpha$ and HIF- $2 \alpha$ increase in luciferase expression was further potentiated in cells incubated in $1 \% \mathrm{O}_{2}$ (Fig. 5E). Deletion analysis showed that the HIF-responsive site on the Angptl3 promoter was within the first $100 \mathrm{bp}$ (base pairs) of the proximal pro- moter; however, no consensus HIF response element (HRE) was found in this site (Fig. 5F). Furthermore, in vivo ChIP assays failed to demonstrate HIF- $2 \alpha$ binding to the promoter (data not shown). Together, these data suggest that Angptl3 is a rapid HIF- $2 \alpha$ responsive gene through a yet-unknown mechanism.

HIF-2 $\alpha$ Regulates Liver Fibrogenesis. A dramatic induction of genes important in liver fibrosis were observed in the gene-expression profiling data. Increases in several fibrogenic genes were confirmed in $V h l^{\mathrm{F} / \mathrm{F} ; A l b E R c r e}$ mice treated with tamoxifen, compared to littermate control mice (Fig. 6A). A specific increase in lysyl oxidase-like 1 ( $L O X L 1)$, lysyl oxidase-like 2 (LOXL2), prolyl 4-hydroxylase alpha 1 (P4HA1), prolyl 4-hydroxylase alpha 2 (P4HA2), procollagenlysine, 2-oxoglutarate 5-dioxygenase 2 (PLOD2), and transglutaminase 2 (TGM2) was observed. These genes are critical for the formation and stabilization of collagen. ${ }^{21-26}$ In addition, smooth muscle actin (SMA), a 

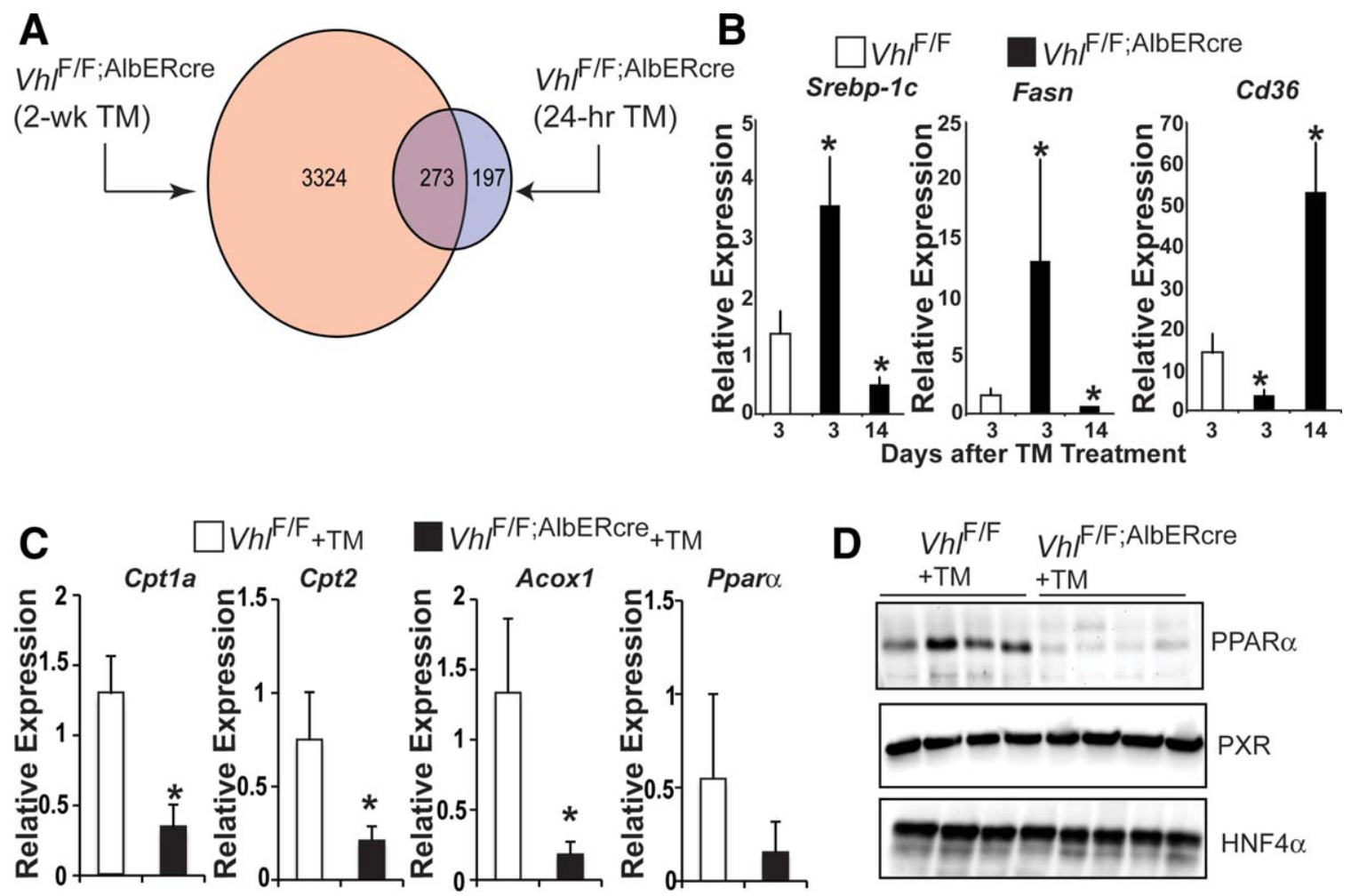

Fig. 4. HIF-2 $\alpha$ modulates lipid homeostatic genes in the liver. (A) Global gene-expression profiling was assessed in liver RNAs isolated from $\mathrm{Vhl}^{\mathrm{F} / \mathrm{F}}$ and $\mathrm{Vh} \mathrm{F}^{\mathrm{F} / \mathrm{F} \text {;AlbERcre }}$ mice treated with tamoxifen (TM) and killed 24 hours or 14 days post-treatment. Four mice were used for each treatment group. (B) GRT-PCR analysis of sterol regulatory element binding factor-1C (Srebp-1c), fatty acid synthase (Fasn), and Cd36 in livers from Vh//F and $V h I^{F / F ; A l b E R c r e}$ mice treated with TM and killed 3 or 14 days post-treatment. Expression was normalized to $\beta$-actin. (C) qRT-PCR analysis of $\beta$-oxidation genes, carnitine palmitoyltransferase 1A (Cpt1a), carnitine palmitoyltransferase 2 (Cpt2), acyl-CoA oxidase 1 (Acox), and peroxisome proliferator-activated receptor alpha $(P p a r \alpha)$ in livers from $V h l^{F / F}$ and $V h l^{F / F ; A l b E R c r e ~ m i c e ~ t r e a t e d ~ w i t h ~ T M ~ a n d ~ k i l l e d ~} 14$ days post-treatment. Expression was normalized to $\beta$-actin. Seven to nine mice were assessed per each treatment group. (D) Western blot analysis measuring PPAR $\alpha$, pregnane $\mathrm{X}$ receptor (PXR), and hepatic nuclear factor 4 (HNF-4 $\alpha$ ) expression from livers in $\mathrm{Vhl}^{\mathrm{F} / \mathrm{F}}$ and $\mathrm{Vhl} \mathrm{l}^{\mathrm{F} / \mathrm{F} \text {; AlbERcre }}$ mice treated with TM and killed 14 days post-treatment. Each bar graph represents the mean value $\pm \mathrm{SD}$. ${ }^{*} P<0.05$.

marker of stellate cell activation and fibrosis, was significantly increased in $V h^{\mathrm{F} / F \text {; AlbERcre }}$ mice treated with tamoxifen, compared to littermate control mice, as assessed by qRT-PCR and western blot analysis (Fig. 6A,B). To confirm an increase in fibrosis, Masson's trichrome staining was performed (Fig. 6C,D). Livers isolated from $V h h^{\mathrm{F} / \mathrm{F} ; A l b E R c r e}$ mice 14 days after tamoxifen treatment demonstrated a moderate increase in focal areas of fibrosis, compared to similarly treated $V h t^{\mathrm{F} / \mathrm{F}}$ mice (Fig. 6C). Moreover, $V h t^{\mathbb{F} / \mathrm{F}}$ and $V h t^{\mathrm{F} / \mathrm{F} ; A l b E R c r e}$ mice were treated with tamoxifen, then put on liquid diet consisting of $4 \%$ ethanol for 2 weeks. Mice are resistant to alcoholinduced fibrosis, as chronic treatment with alcohol (i.e., over 3 months) typically results in no marked liver fibrogenesis in mice. ${ }^{27}$ However, in mice with a disruption of liver $\mathrm{Vhl}$, alcohol treatment caused marked fibrosis, compared with littermate controls treated with alcohol (Fig. 6D). The double disruption of $V h l$ and Hif-2 $\alpha$ $\left(V t^{\mathrm{F} / \mathrm{F}} H\right.$ if $2 a^{\mathrm{F} / \mathrm{F} ; \mathrm{AlbER} c r e}+$ tamoxifen) ameliorated the increase in SMA, whereas a significant increase in SMA expression was observed in mice with a double disrup- tion of $V h l$ and Hif- $1 \alpha \quad\left(V h l^{\mathrm{F} / \mathrm{F}} \mathrm{Hifl}^{\mathrm{F} / \mathrm{F} ; \mathrm{AlbER} c r e}+\right.$ tamoxifen) (Fig. 7A). Similarly, the increase in fibrosis observed in $\mathrm{Vhl}$-disrupted mice on an alcohol diet was completely lost in the $V h l$ and Hif-2 $\alpha$ double knockout, but not the $V h l$ and Hif- $1 \alpha$ double knockout (Fig. 7B). Consistent with the role of HIF-2 $\alpha$ in exacerbating fibrosis, fibrogenic gene-expression levels were not increased in the Vhl and Hif- $2 \alpha$ knockout, as compared to mice with a $V h l$ disruption (Fig. 7C). Together, these data demonstrate that HIF- $2 \alpha$ is a critical transcription factor in exacerbating fibrosis in the liver.

HIF-2 $\alpha$ Directly Regulates Several Profibrogenic Genes. To assess whether HIF- $2 \alpha$ could directly regulate fibrogenic genes in the liver, ChIP assays were performed using cross-linked liver DNA isolated from tamoxifen-treated $V h l^{\mathrm{F} / \mathrm{F}}$ and $V h l^{\mathrm{F} / \mathrm{F} \text {;AlbERcre }}$ mice, with the average shearing size of $1.5 \mathrm{~kb}$. Primers were designed to the center of the proximal promoter to assess HIF- $2 \alpha$ occupancy. This method provides an assessment of HIF- $2 \alpha$ occupancy at promoters without defining the precise HIF response element. With this 
Fig. 5. HIF-2 $\alpha$ increases angiopoietin-like 3 (Angptl3) expression in the liver. (A) qRT-PCR analysis of Angpt/3 in livers from $V h l^{F / F}$ and $V h l^{F / F ; A l b E R c r e ~ m i c e ~ t r e a t e d ~ w i t h ~ t a m o x i f e n ~ a n d ~}$ killed 3,7 , or 14 days post-treatment. Expression was normalized to $\beta$-actin. Seven to nine mice were assessed per each treatment group. (B) Western blot analysis measuring ANGPTL3 expression in livers from $\mathrm{Vhl}^{\mathrm{F} / \mathrm{F}}$ and $V h l^{\mathrm{F} / F}$;AlbERcre mice treated with tamoxifen and killed 14 days post-treatment. Expression was normalized to GAPDH protein expression. (C) Serum-triglyceride analysis measuring from $V h l^{\mathrm{F} / \mathrm{F}}$ and $\mathrm{Vh} \mathrm{l}^{\mathrm{F} / \mathrm{F} ; \mathrm{Alb} \text {-Rcre }}$ mice treated with tamoxifen and killed 14 days post-treatment. Seven to nine mice were assessed per each treatment group. (D) Hepa-1 cells were transfected with increasing amounts of mouse Angptl3. Forty-eight hours post-transfection, cells were washed and stained with oil red 0 or Western analysis performed to verify overexpression (top panel). Oil red 0 accumulation was quantitated in isopropanolic extracts of the cells, and data were normalized to protein content (bottom panel). (E) Luciferase-reporter constructs under the control of the $(E) 1.7-k b$ regulatory region of the mouse Angpt/3 gene or $(F) 5^{\prime}$ deletion constructs of the Angpt/3 promoter. Hepa-1 cells transiently transfected with the luciferase construct, and cotransfected with empty vector, HIF- $1 \alpha$, or HIF- $2 \alpha$ expression plasmids. Standard dual-luciferase assays were performed on cells incubated in normal or hypoxic cell-culture conditions. Each bar graph represents the mean value \pm SD. $O D$, optical density; RLU, relative luciferase units. ${ }^{*} P<0.05$.
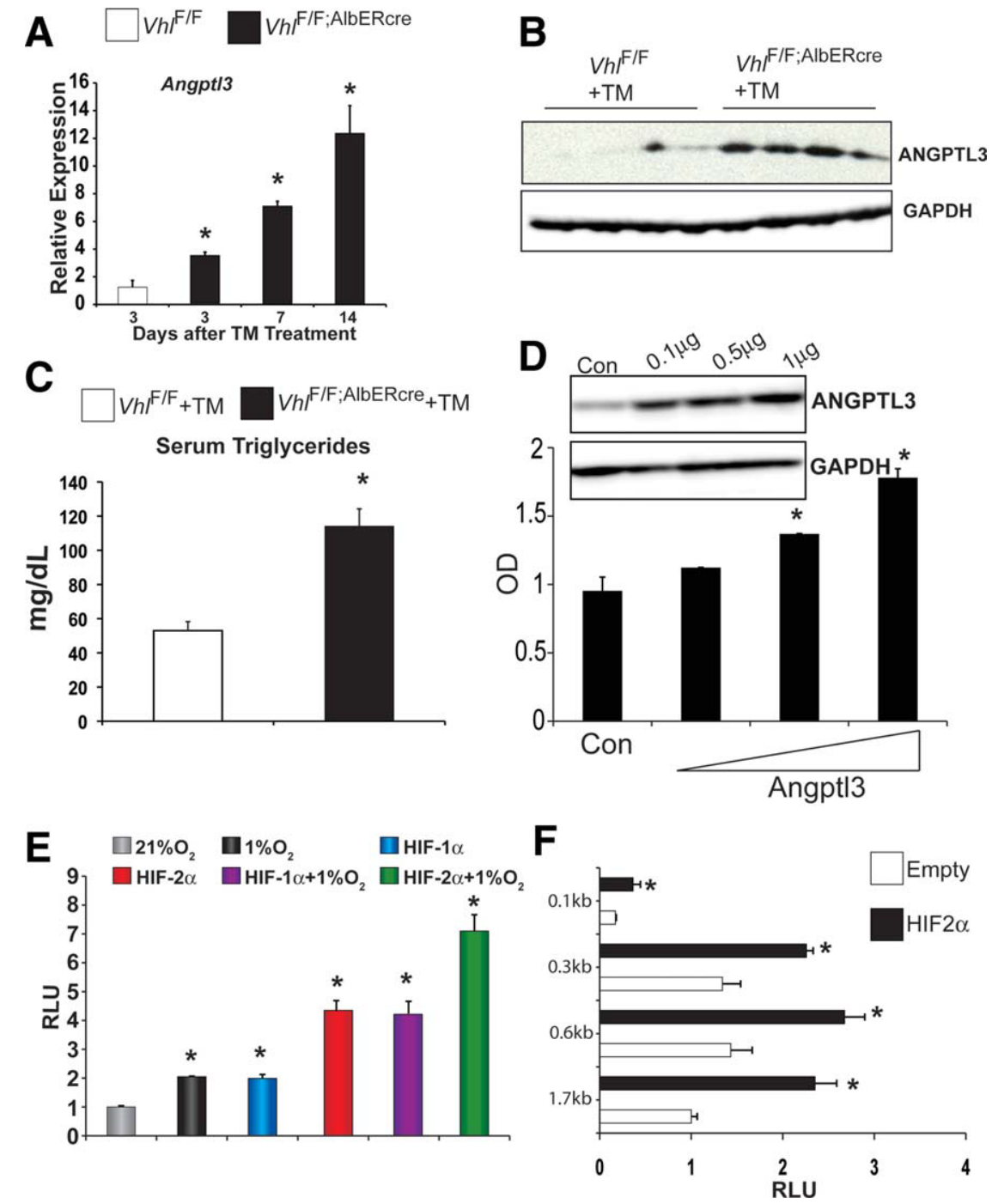

method, it was shown that HIF- $2 \alpha$ was enriched at the promoters of several fibrogenic genes in $V h^{\mathrm{F} / F \text {;AlbERcre }}$ mice, compared with control littermates (Fig. 8A). To assess whether the low-resolution ChIP assays, indeed, did identify direct targets, TGM2 expression was further assessed. An increase in TGM2 protein expression was observed in $V h l^{\mathrm{F} / \mathrm{F} \text {;AlbERcre }}$ mice, compared to control littermates, after 2 weeks of $V h l$ disruption (Fig. $8 \mathrm{~B})$. Next, a $\operatorname{Tgm} 2$ proximal promoter luciferase construct was cotransfected into liver-derived Hepa-1 cells with a mammalian expression plasmid for HIF- $1 \alpha$, HIF$2 \alpha$, or empty vector. HIF- $2 \alpha$ specifically induced luciferase expression, whereas HIF-1 $\alpha$ had no effect, compared with empty vector transfected control (Fig. 8C), and mutating the two putative HREs ablated HIF- $2 \alpha$ activity (Fig. 8D). Using primers flanking the HREs and sheared cross-linked liver DNA (shearing size, 300 bp) from tamoxifen-treated $V h t^{\mathbb{F} / \mathrm{F}}$ and $V h t^{\mathbb{F} / F ; A l b E R c r e}$ mice demonstrated increased HIF- $2 \alpha$ binding to the $\operatorname{Tgm} 2$ promoter in livers isolated from $V h t^{\mathbb{F} / F ; A l b E R c r e}$ mice, compared to $V h t^{\mathbb{F} / \mathrm{F}}$ mice (Fig. 8E). These data demonstrate that HIF$2 \alpha$ can directly regulate fibrogenic genes.

\section{Discussion}

One-third of adults in the United States are diagnosed with fatty liver disease, mostly attributed to obesity or alcohol consumption. Approximately $10 \%$ will proceed to develop steatohepatitis and associated comorbidities (e.g., fibrosis, cirrhosis, and liver cancer). ${ }^{28}$ Currently, the mechanisms for the increased progression are not known. However, according to the two-hit hypothesis, the initial insult is the fat accumulation within the liver, with the second insult being increased oxidative stress and inflammation, and both are critical for steatohepatitis. ${ }^{29}$ The current study demonstrates that mice with a temporal hepatic disruption of $V h l$ have spontaneous fatty liver and liver 


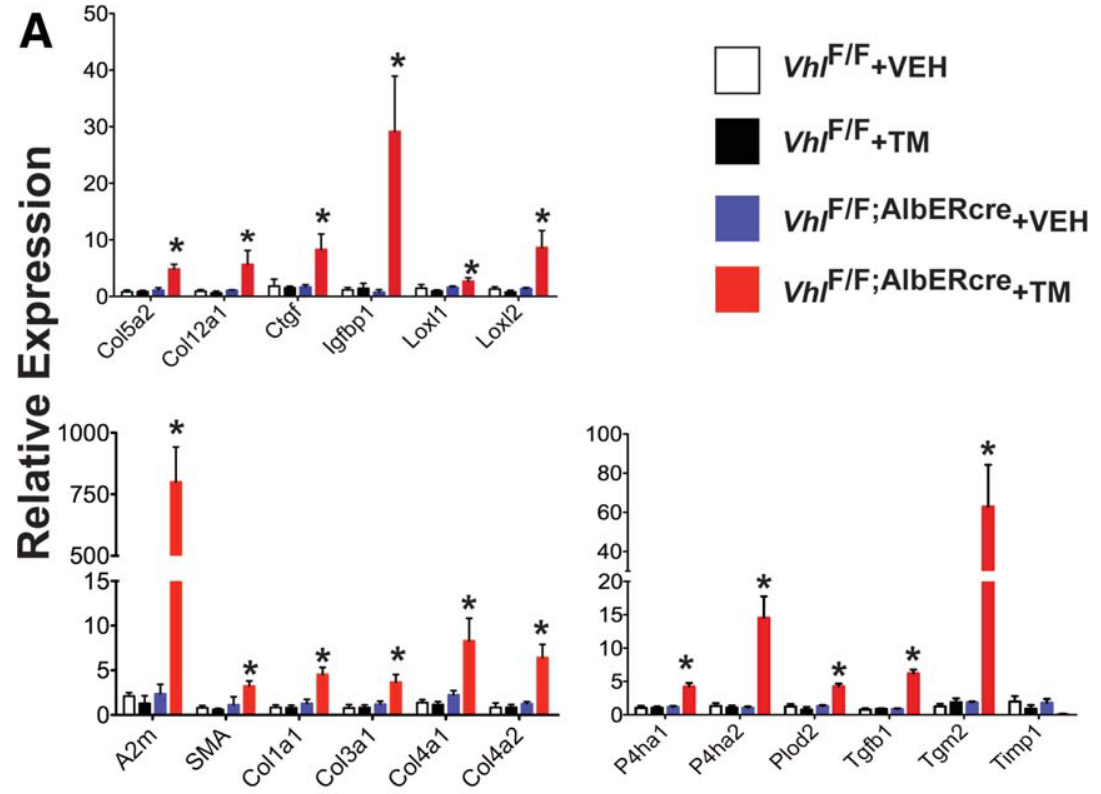

B

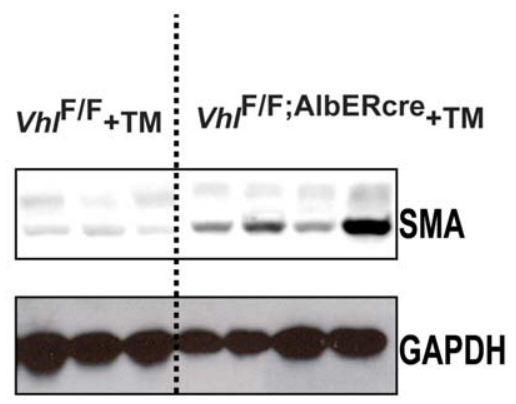

C $V h l^{\mathrm{F} / \mathrm{F}}+\mathrm{TM}$

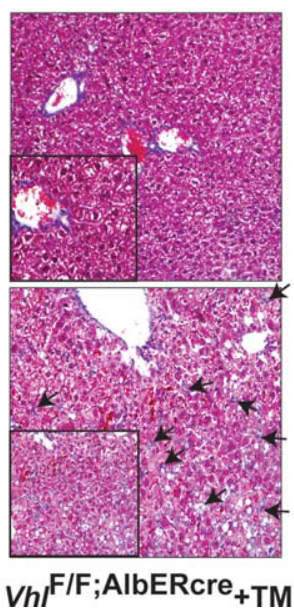

inflammation that will progress to focal fibrosis and hepatomegaly in a HIF- $2 \alpha$-dependent manner. This demonstrates that hypoxia and HIF-2 $\alpha$ play a critical role in both insults needed for the progression of fatty liver disease, as suggested by the two-hit hypothesis.

Gene-expression profiling demonstrated that several genes important in fatty acid synthesis, uptake, and $\beta$-oxidation are significantly altered after the loss of VHL. Fasn and Srebp-1c were repressed in mice with a conditional disruption of $V h l$; therefore, fatty acid synthesis was not thought to be involved in increased lipid accumulation in the liver after $V h l$ disruption. ${ }^{14}$ However, the present data suggest that at early times points, lipid synthesis may contribute to steatosis, as both Fasn and Srebp-1c are significantly increased after acute disruption, then are significantly repressed after long-term $V h l$ deficiency. To assess whether, indeed, at

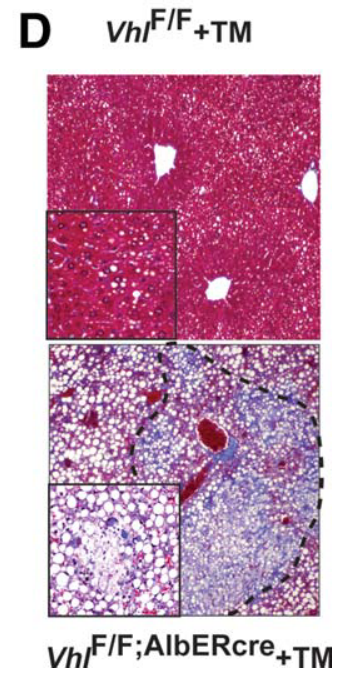

Fig. 6. Disruption of $V h l$ increases liver fibrosis. (A) qRT-PCR analysis measuring expression of fibrogenic genes in livers of $\mathrm{Vhl}^{\mathrm{F} / \mathrm{F} ; \text { AlbERcre }}$ or $\mathrm{Vh} \mathrm{F}^{\mathrm{F} / \mathrm{F}}$ mice treated with vehicle (VEH) or tamoxifen (TM) and killed 14 days posttreatment. Expression was normalized to $\beta$-actin. Seven to nine mice were assessed per each treatment group. (B) Western blot analysis measuring SMA expression in livers from $V h l^{F / F}$ and $\mathrm{Vh} \mathrm{l}^{\mathrm{F} / \mathrm{F} ; A l b E R c r e}$ mice treated with tamoxifen and killed 14 days post-treatment. (C,D) Masson's trichrome-stained livers from $V h l^{\mathrm{F} / \mathrm{F}}$ and $\mathrm{Vh} \mathrm{l}^{\mathrm{F} / \mathrm{F} \text {;AlbERcre }}$ mice treated with tamoxifen and killed 14 days post-treatment on $(C)$ normal chow diet or (D) liquid alcohol diet. Fibrotic cells are indicated by arrows or are outlined by a dashed line. Seven to nine mice were assessed per each treatment group. Each bar graph represents the mean value $\pm \mathrm{SD} .{ }^{*} P<$ 0.05 and $n=7-9$ mice per each treatment group.

early time points after HIF activation that fatty acid synthesis was increased, ACC activity was measured. However, both phosphorylated and total ACC were significantly repressed at 3 days after tamoxifen treatment in the $V h t^{\mathbb{E} / F \text {;AlbERcre }}$ mice, compared with $V h t^{\mathbb{F} / F}$ mice, making the data difficult to interpret (Supporting Fig. 5). However, 14 days after tamoxifen treatment, no change in phosphorylated or total ACC was

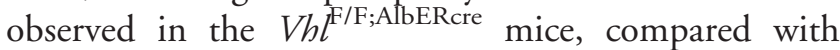
$V h b^{\mathrm{F} / F}$ mice, suggesting that $\beta$-oxidation may be a critical driver in fat accumulation at later time points. In addition, the gene-expression analysis demonstrates a significant modulation of several nuclear receptor target genes (e.g., liver X receptor, farnesoid X receptor, and PPAR $\gamma$ ). However, changes were not found in the expression of these nuclear receptors by qRT-PCR or microarray analysis, suggesting that nuclear receptors 
A
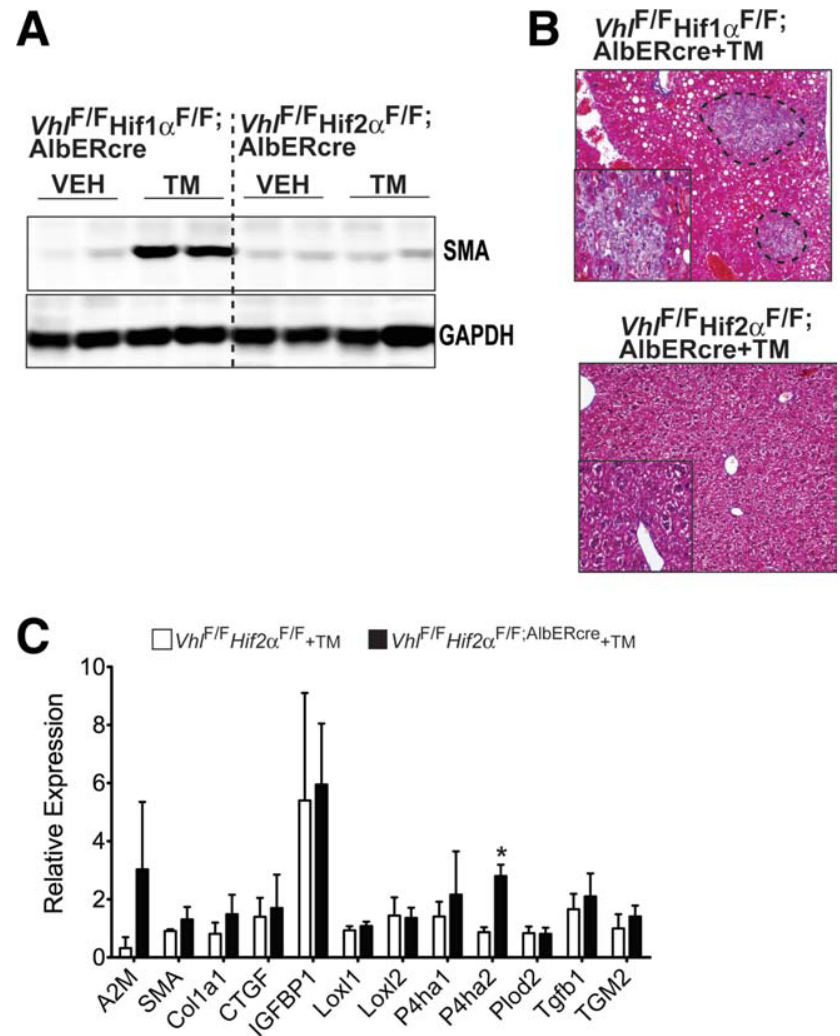

Fig. 7. HIF-2 $\alpha$ activation increases liver fibrosis. (A) Western blot analysis of SMA from livers of $\mathrm{Vhl} l^{\mathrm{F} / \mathrm{F}} H i f 1 \alpha^{\mathrm{F} / \mathrm{F} ; A l b E R c r e}$ and $\mathrm{Vhl} / \mathrm{F} / \mathrm{F}$ Hif $2 \alpha^{\mathrm{F} / F ; A l b E R c r e}$ mice treated with tamoxifen (TM) and killed 14 days post-treatment. Expression was normalized to GAPDH protein expression. (B) Masson's trichrome-stained livers from $V h l^{\mathrm{F} / \mathrm{F}} H i f 1 \alpha^{\mathrm{F} / F}$;AlbERcre and $\mathrm{Vhl} l^{\mathrm{F} / \mathrm{F}} \mathrm{Hif2} \alpha^{\mathrm{F} / \mathrm{F} ; \text { AlbERcre }}$ mice treated with tamoxifen and killed 14 days post-treatment on a liquid alcohol diet. Fibrotic cells are indicated by arrows or are outlined by a dashed line. Seven to nine mice were assessed per each treatment group. (C) qRT-PCR analysis measuring expression of fibrogenic genes in livers of $\mathrm{hhl}^{\mathrm{F} / \mathrm{F}} \mathrm{Hifl}^{\mathrm{F}} \mathrm{\alpha}^{\mathrm{F} \text {; AlbERcre }}$ or $\mathrm{Vhl}{ }^{\mathrm{F} / \mathrm{F}} \mathrm{Hif} 2 \alpha^{\mathrm{F} / \mathrm{F}}$ mice treated with tamoxifen (TM) and killed 14 days post-treatment. Expression was normalized to $\beta$-actin. Seven to nine mice were assessed per each treatment group. Each bar graph represents the mean value $\pm \mathrm{SD}$. ${ }^{*} P<0.05$.

are not direct transcriptional targets of HIF. Interestingly, in mice with the conditional $V h l$ deletion, adipose differentiation-related protein (ADFP) was significantly induced and thought to be critical in the liver steatotic phenotype. ${ }^{14}$ However, in the $V h t^{\mathrm{F} / F ; A l b E R c r e}$ mice after tamoxifen treatment, no increase in ADFP was observed at any time point assessed (data not shown), suggesting that the increase in ADFP is a late secondary response or because of developmental defects after conditional $V h l$ disruption. These data highlight the importance of temporal gene disruption of $V h l$ to identify direct mediators of response.

One important mediator of lipid homeostasis, ANGPTL3, an endogenous lipoprotein lipase (LPL) inhibitor, ${ }^{30-32}$ was identified as an HIF-responsive gene. ANGPTL3 is important in regulating serum tri- glycerides levels. ${ }^{20}$ In tamoxifen-treated $V h l^{\mathrm{F} / \mathrm{F} ; \mathrm{AlbER} \text { cre }}$ mice, the increase of ANGPTL3 correlated to an increase in serum triglycerides, and ANGPTL3 directly increased lipid accumulation in Hepa-1 cells, as assessed by oil red $\mathrm{O}$ staining. Currently, it is not known whether the increase in lipid accumulation is through the LPL inhibitor function of ANGPTL3, but is a clear point of emphasis for future studies. Angptl3 gene expression and promoter activity were rapidly induced by HIF- $2 \alpha$. However, no HREs were identified in the promoter, suggesting that its activation is HIF- $2 \alpha$-mediated through an indirect mechanism. The HIF-responsive region was localized to a 100-bp region directly proximal to the transcription initiation site, and HIF- $2 \alpha$ regulation of this sequence is being further assessed.

During the preparation of this article, others published similar findings in a temporally deleted, liverspecific VHL mouse model, in which disruption of $V h l$ was induced by tail vein injection of adenovirus encoding cre recombinase (ad-Cre). ${ }^{33}$ Five days after an injection of ad-Cre, mice demonstrated dramatic steatosis and a decrease in PPAR $\alpha$ signaling, thus establishing, as does the present study, that HIF signaling has a primary role in liver lipid homeostasis. Furthermore, the present study demonstrates that these are immediate, rapid responses of HIF- $2 \alpha$ signaling. Interestingly, after ad-Cre injection, mice demonstrated rapid death in an HIF-dependent manner, where the median survival was 6 days. ${ }^{34}$ The increase in survival in the $V h t^{\mathbb{F} / F ; \text { AlbERcre }}$ mice after tamoxifen administration allowed further assessment of the livers, revealing increased progression of steatosis to inflammation. Thus, $V h t^{\mathbb{F} / \mathrm{F} ; \mathrm{AlbER} \text { cre }}$ mice may be a valuable model of spontaneous steatohepatitis for use in preclinical drug development.

Although the direct effectors that increase inflammation are not known, it is possible that HIF- $2 \alpha$ can directly activate inflammatory mediators in the liver. Indeed, it was shown that $\mathrm{Il}-6$ is a direct HIF- $2 \alpha \operatorname{tar}$ get gene in macrophages. ${ }^{34}$ However, our data clearly show that HIF- $2 \alpha$ can bind to the promoters of several profibrogenic genes, consistent with data demonstrating that hypoxia can activate fibrogenesis in hepatocytes and stellate cells. ${ }^{35-37}$ Hepatic stellate cells initiate the fibrotic process. In the liver, quiescent stellate cells are critical in the storage of vitamin A. During liver injury, stellate cells become activated, proliferate, and express a fibrogenic gene program. ${ }^{38}$ After $V h l$ disruption, a robust activation of stellate cells is observed in the liver resulting from high activation of collagen gene expression and an increase in SMA, both markers of stellate cell activation. The initiating factor in the activation of stellate cells after $V h l$ loss is thought to 


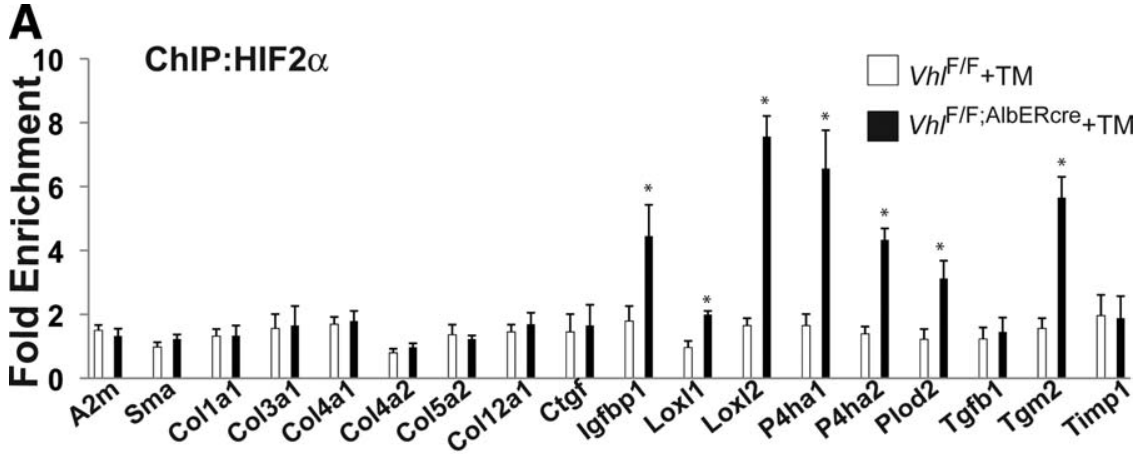

B

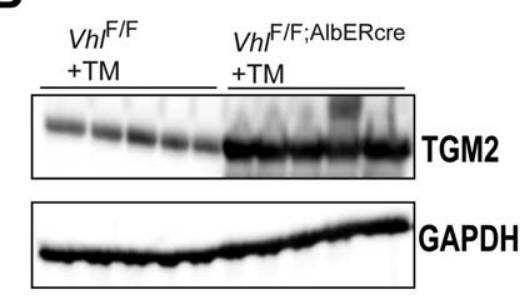

D

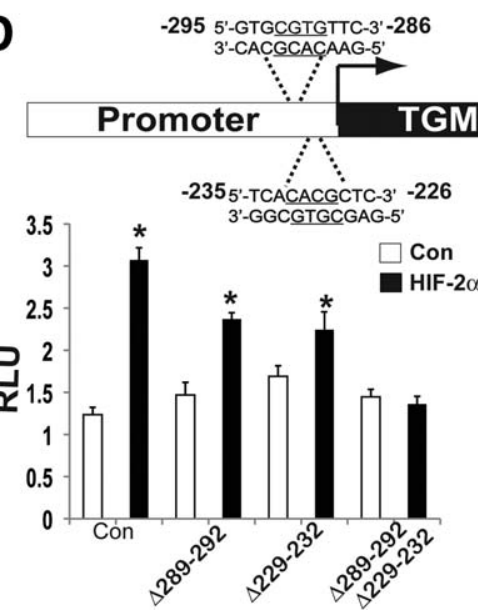

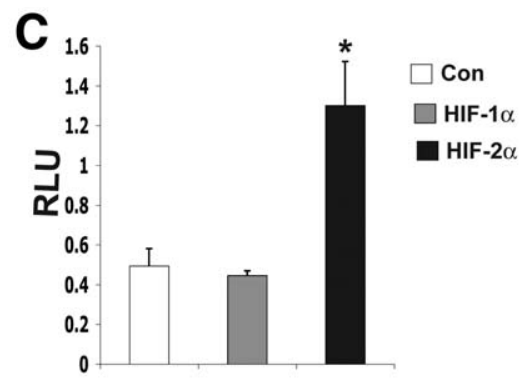

E

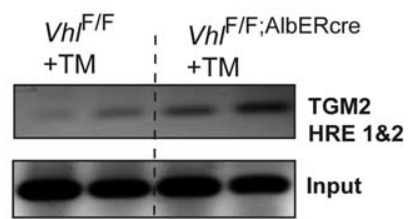

Fig. 8. HIF- $2 \alpha$ can directly bind to promoters of fibrogenic genes in the liver. (A) ChIP assays of livers from $V h l^{F / F ; A l b E R c r e ~ o r ~}$ $\mathrm{Vh} \mathrm{F}^{\mathrm{F} / \mathrm{F}}$ treated with tamoxifen (TM) and killed 3 days post-treatment using HIF- $2 \alpha$-specific antibody. Data are expressed as fold enrichment over control immunoglobulin G (IgG) and normalized to input. Seven to nine mice were assessed per each treatment group. (B) Western blot analysis measuring TGM2 expression in livers from $V h l^{F / F}$ and $V h F^{F / F ; A l b e R c r e ~ m i c e ~}$ treated with tamoxifen and killed 14 days post-treatment. Expression was normalized to GAPDH. (C) Luciferase-reporter constructs under the control of the 1-kb regulatory region of the mouse Tgm2 gene. Hepa-1 cells transiently transfected with the luciferase construct and cotransfected with empty vector, HIF- $1 \alpha$, or HIF- $2 \alpha$ expression plasmids. Standard dual-luciferase assays were performed. (D) Tgm2 promoter illustrating the HREs in the regulatory region. Upstream regions are numbered in relation to the transcription initiation site, which is designated +1 (top panel). HRE deleted Tgm2 luciferase-reporter was cotransfected with empty vector or HIF- $2 \alpha$ expression plasmids (bottom panel). Standard dual-luciferase assays were performed. (E) ChIP assays of livers from $V h l^{F / F ; A l b E R c r e ~ o r ~}$ $V h l^{\mathrm{F} / \mathrm{F}}$ treated with tamoxifen (TM) and killed 3 days post-treatment using HIF- $2 \alpha$-specific antibody. Primers flanking the two HREs were used for PCR. Each bar graph represents the mean value \pm SD. ${ }^{*} P<0.05$. Three to five mice were assessed per each treatment group. RLU, relative luciferase units. be the result of a sustained increase in lipid accumulation and inflammatory genes. In addition, the increase in fibrosis mediated by HIF- $2 \alpha$ may be caused by collagen matrix stabilization. P4HA1, P4HA2, and PLOD2 are required for hydroxylation of lysyl and prolyl residues on collagen. ${ }^{23,26}$ The resultant hydroxylysyl and hydroxyproline groups are critical for the stability and synthesis of collagen matrixes. Loxl1 and loxl2 gene expression were also increased in the livers of tamoxifen-treated $V h l^{\mathrm{F} / \mathrm{F} \text {;AlbERcre }}$ mice, and their respective promoters were occupied by HIF- $2 \alpha$. Lysyl oxidase activity is critical in the formation of insoluble collagen fibers, and HIF- $1 \alpha$ has been shown to increase renal fibrosis through a lysyl oxidase-mediated mechanism. ${ }^{21,22}$ Moreover, TGM2, a multifunction enzyme that covalently cross-links collagen matrices, has been shown to be critical in inducing apoptosis by inactivation of SP1 and c-met in injured livers after alcohol administration. ${ }^{24,25}$ HIF- $2 \alpha$ can directly regulate the promoter of $\operatorname{Tgm} 2$ in a distinct manner, as observed with HIF- $1 \alpha .{ }^{39}$ It is not clear whether Tgm2 is the key enzyme that regulates fibrosis, because Tgm2-null mice are not protected in the carbon tetrachloride and the thioacetamide-induced fibrosis models. ${ }^{40}$ However, it is likely that the cumulative increase in several profibrogenic genes are needed to increase liver fibrosis, and HIF- $2 \alpha$ may be the critical transcription factor to integrate these signals.

The present study demonstrates that activation of HIF- $2 \alpha$ in the liver regulates liver homeostasis and disease progression and establishes that steatosis, inflammation, and fibrosis are direct responses initiated by the liver after HIF- $2 \alpha$ activation. In addition, the present work provides a novel animal model to study the 
precise molecular and genetic changes required for the progression of fatty liver disease to steatohepatitis. Together, these findings may lead to novel therapies for liver injury.

\section{References}

1. Jungermann K. Metabolic zonation of liver parenchyma. Semin Liver Dis $1988 ; 8: 329-341$.

2. Jungermann K, Kietzmann T. Oxygen: modulator of metabolic zonation and disease of the liver. Hepatology 2000;31:255-260.

3. Ivan M, Kondo K, Yang H, Kim W, Valiando J, Ohh M, et al. HIFalpha targeted for VHL-mediated destruction by proline hydroxylation: implications for O2 sensing. Science 2001;292:464-468.

4. Jaakkola P, Mole DR, Tian YM, Wilson MI, Gielbert J, Gaskell SJ, et al. Targeting of HIF-alpha to the von Hippel-Lindau ubiquitylation complex by O2-regulated prolyl hydroxylation. Science 2001;292:468-472.

5. Semenza GL, Wang GL. A nuclear factor induced by hypoxia via de novo protein synthesis binds to the human erythropoietin gene enhancer at a site required for transcriptional activation. Mol Cell Biol 1992;12:5447-5454.

6. Tian H, McKnight SL, Russell DW. Endothelial PAS domain protein 1 (EPAS1), a transcription factor selectively expressed in endothelial cells. Genes Dev 1997;11:72-82.

7. Wang GL, Jiang BH, Rue EA, Semenza GL. Hypoxia-inducible factor 1 is a basic-helix-loop-helix-PAS heterodimer regulated by cellular O2 tension. Proc Natl Acad Sci U S A 1995;92:5510-5514.

8. Wang GL, Semenza GL. Characterization of hypoxia-inducible factor 1 and regulation of DNA binding activity by hypoxia. J Biol Chem 1993;268:21513-21518.

9. Haase VH, Glickman JN, Socolovsky M, Jaenisch R. Vascular tumors in livers with targeted inactivation of the von Hippel-Lindau tumor suppressor. Proc Natl Acad Sci U S A 2001;98:1583-1588.

10. Park SK, Haase VH, Johnson RS. von Hippel Lindau tumor suppressor regulates hepatic glucose metabolism by controlling expression of glucose transporter 2 and glucose 6-phosphatase. Int J Oncol 2007;30:341-348.

11. Peyssonnaux C, Zinkernagel AS, Schuepbach RA, Rankin E, Vaulont S, Haase $\mathrm{VH}$, et al. Regulation of iron homeostasis by the hypoxia-inducible transcription factors (HIFs). J Clin Invest 2007;117:1926-1932.

12. Rankin EB, Biju MP, Liu Q, Unger TL, Rha J, Johnson RS, et al. Hypoxia-inducible factor-2 (HIF-2) regulates hepatic erythropoietin in vivo. J Clin Invest 2007;117:1068-1077.

13. Rankin EB, Rha J, Unger TL, Wu CH, Shutt HP, Johnson RS, et al. Hypoxia-inducible factor-2 regulates vascular tumorigenesis in mice. Oncogene 2008;27:5354-5358.

14. Rankin EB, Rha J, Selak MA, Unger TL, Keith B, Liu Q, et al. Hypoxia-inducible factor 2 regulates hepatic lipid metabolism. Mol Cell Biol 2009;29:4527-4538.

15. Matsusue K, Miyoshi A, Yamano S, Gonzalez FJ. Ligand-activated PPARbeta efficiently represses the induction of LXR-dependent promoter activity through competition with RXR. Mol Cell Endocrinol 2006;256:23-33.

16. Taylor M, Qu A, Anderson ER, Matsubara T, Martin A, Gonzalez FJ, et al. Hypoxia-inducible factor-2alpha mediates the adaptive increase of intestinal ferroportin during iron deficiency in mice. Gastroenterology 2011; doi:10.1053/j.gastro.2011.03.007.

17. Schuler M, Dierich A, Chambon P, Metzger D. Efficient temporally controlled targeted somatic mutagenesis in hepatocytes of the mouse. Genesis 2004;39:167-172.

18. Romeo S, Yin W, Kozlitina J, Pennacchio LA, Boerwinkle E, Hobbs $\mathrm{HH}$, et al. Rare loss-of-function mutations in ANGPTL family members contribute to plasma triglyceride levels in humans. J Clin Invest 2009;119:70-79.

19. Conklin D, Gilbertson D, Taft DW, Maurer MF, Whitmore TE, Smith $\mathrm{DL}$, et al. Identification of a mammalian angiopoietin-related protein expressed specifically in liver. Genomics 1999;62:477-482.
20. Koishi R, Ando Y, Ono M, Shimamura M, Yasumo H, Fujiwara T, et al. Angptl3 regulates lipid metabolism in mice. Nat Genet 2002;30: 151-157.

21. Higgins DF, Kimura K, Bernhardt WM, Shrimanker N, Akai Y, Hohenstein B, et al. Hypoxia promotes fibrogenesis in vivo via HIF-1 stimulation of epithelial-to-mesenchymal transition. J Clin Invest 2007; 117:3810-3820.

22. Kagan HM. Lysyl oxidase: mechanism, regulation and relationship to liver fibrosis. Pathol Res Pract 1994;190:910-919.

23. Myllyharju J. Prolyl 4-hydroxylases, the key enzymes of collagen biosynthesis. Matrix Biol 2003;22:15-24.

24. Strnad P, Omary MB. Transglutaminase cross-links Sp1-mediated transcription to ethanol-induced liver injury. Gastroenterology 2009;136: 1502-1505.

25. Tatsukawa H, Fukaya Y, Frampton G, Martinez-Fuentes A, Suzuki K, Kuo TF, et al. Role of transglutaminase 2 in liver injury via cross-linking and silencing of transcription factor Sp1. Gastroenterology 2009; 136:1783.e10-1795.e10.

26. van der Slot AJ, Zuurmond AM, Bardoel AF, Wijmenga C, Pruijs HE, Sillence DO, et al. Identification of PLOD2 as telopeptide lysyl hydroxylase, an important enzyme in fibrosis. J Biol Chem 2003;278: 40967-40972.

27. Lieber CS, DeCarli LM. Animal models of chronic ethanol toxicity. Meth Enzymol 1994;233:585-594.

28. Somsouk M, Yee HF Jr, Biggins SW. Understanding liver health using the National Center for Health Statistics. Dig Dis Sci 2009;54: 2325-2329.

29. Day CP, James OF. Steatohepatitis: a tale of two "hits"? Gastroenterology 1998;114:842-845.

30. Shimizugawa T, Ono M, Shimamura M, Yoshida K, Ando Y, Koishi R, et al. ANGPTL3 decreases very low density lipoprotein triglyceride clearance by inhibition of lipoprotein lipase. J Biol Chem 2002;277: 33742-33748.

31. Shan L, Yu XC, Liu Z, Hu Y, Sturgis LT, Miranda ML, Liu Q. The angiopoietin-like proteins ANGPTL3 and ANGPTL4 inhibit lipoprotein lipase activity through distinct mechanisms. J Biol Chem 2009; 284:1419-1424.

32. Lee EC, Desai U, Gololobov G, Hong S, Feng X, Yu XC, et al. Identification of a new functional domain in angiopoietin-like 3 (ANGPTL3) and angiopoietin-like 4 (ANGPTL4) involved in binding and inhibition of lipoprotein lipase (LPL). J Biol Chem 2009;284:13735-13745.

33. Kucejova B, Sunny NE, Nguyen AD, Hallac R, Fu X, Pena-Llopis S, et al. Uncoupling hypoxia signaling from oxygen sensing in the liver results in hypoketotic hypoglycemic death. Oncogene 2011;30:2147-2160.

34. Imtiyaz HZ, Williams EP, Hickey MM, Patel SA, Durham AC, Yuan LJ, et al. Hypoxia-inducible factor 2alpha regulates macrophage function in mouse models of acute and tumor inflammation. J Clin Invest 2010;120:2699-2714

35. Copple BL, Bustamante JJ, Welch TP, Kim ND, Moon JO. Hypoxiainducible factor-dependent production of profibrotic mediators by hypoxic hepatocytes. Liver Int 2009;29:1010-1021.

36. Copple BL, Bai S, Moon JO. Hypoxia-inducible factor-dependent production of profibrotic mediators by hypoxic Kupffer cells. Hepatol Res 2010;40:530-539.

37. Copple BL, Bai S, Burgoon LD, Moon JO. Hypoxia-inducible factor1alpha regulates the expression of genes in hypoxic hepatic stellate cells important for collagen deposition and angiogenesis. Liver Int 2011;31: 230-244.

38. Brenner DA. Molecular pathogenesis of liver fibrosis. Trans Am Clin Climatol Assoc 2009;120:361-368.

39. Jang GY, Jeon JH, Cho SY, Shin DM, Kim CW, Jeong EM, et al. Transglutaminase 2 suppresses apoptosis by modulating caspase 3 and NF-kappaB activity in hypoxic tumor cells. Oncogene 2010;29:356-367.

40. Popov Y, Sverdlov DY, Sharma AK, Bhaskar KR, Li S, Freitag TL, et al. Tissue transglutaminase does not affect fibrotic matrix stability or regression of liver fibrosis in mice. Gastroenterology 2011;140: 1642-1652. 